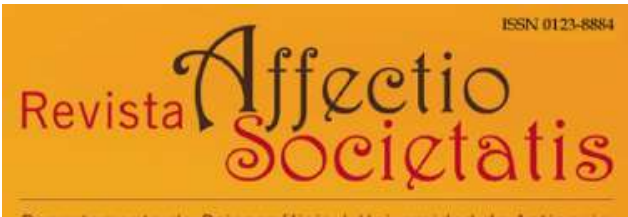

Departamento de Psicoanálisis / Universidad de Antioquia

Revista Affectio Societatis

Departamento de Psicoanálisis

Universidad de Antioquia

revistaaffectiosocietatis@udea.edu.co

ISSN (versión electrónica): 0123-8884

Colombia

2020

Leonardo Barreira Danziato, Paulo Henrique de Oliveira Arruda, Rebeca Guedes Jales Carvalho, Thaís Castro Leite

Da psicologia das massas à multidão: uma nova topología das manifestações sociais

Revista Affectio Societatis, Vol. 17, N. ${ }^{\circ} 33$, julio-diciembre de 2020

Art. \# 11 (pp. 270-297)

Departamento de Psicoanálisis, Universidad de Antioquia

Medellín, Colombia 


\section{DA PSICOLOGIA DAS MASSAS À MULTIDÃO: UMA NOVA TOPOLOGIA DAS MANIFESTAÇÕES SOCIAIS}

Leonardo Barreira Danziato ${ }^{1}$

Universidade de Fortaleza, Brasil

leonardodanziato@unifor.br

http://orcid.org/0000-0002-8870-9123

Paulo Henrique de Oliveira Arruda 2

Universidade de Fortaleza, Brasil

paulohenrique25@gmail.com

https://orcid.org/0000-0003-0914-8602

Rebeca Guedes Jales Carvalho ${ }^{3}$

Universidade de Fortaleza, Brasil

rebecajales@gmai.com

https://orcid.org/0000-0002-6346-2953

Thaís Castro Leite 4

Universidade de Fortaleza, Brasil

thaislialeite@gmail.com

https://orcid.org/0000-0001-5955-1251

DOI: 10.17533/udea.affs.v17n33a11

1 Professor titular, Doutor do Programa de Pós-Graduação em Psicologia da Universidade de Fortaleza/Brasil. Psicanalista, Analista-Membro da Invenção Freudiana - Transmissão da Psicanálise.

2 Mestre em Psicologia pelo Programa de Pós-Graduação em Psicologia da Universidade de Fortaleza/ Brasil. Psicólogo graduado na Universidade de Forteleza.

3 Mestre em Psicologia pelo Programa de Pós-Graduação em Psicologia da Universidade de Fortaleza/ Brasil. Psicóloga graduada na Universidade de Forteleza.

4 Mestre em Psicologia pelo Programa de Pós-Graduação em Psicologia da Universidade de Fortaleza/ Brasil. Psicóloga graduada na Universidade de Forteleza. 


\section{Resumo}

O presente artigo tem como objetivo realizar uma leitura política das novas formas de manifestações sociais, estabelecendo um escopo conceitual que nos permita compreender, inferir e descrever a estrutura topológica dessas manifestações políticas na contemporaneidade. Inicialmente nos servimos primordialmente do conceito de massa descrito por Freud e Canetti, interrogando se este é suficiente para a nossa tarefa ou se na verdade estaríamos diante de uma conjuntura diversa onde o conceito de multidão, tal como formularam Hardt e Negri, seria mais acurado para a nossa leitura. Como conclusão constatamos que as atuais manifestações sociais apresentam características muito mais próximas da topologia da multidão.

Palavras-chave: Massa, multidão, manifestações, topologia.

\section{DE LA PSICOLOGÍA DE MASAS A LA MULTITUD: UNA NUEVA TOPOLOGÍA DE LAS MANIFESTACIONES SOCIALES}

\section{Resumen}

El presente artículo tiene como objetivo realizar una lectura política de las nuevas formas de manifestaciones sociales, para lo cual establece un alcance conceptual que nos permita comprender, inferir y describir la estructura topológica de esas manifestaciones políticas en la contemporaneidad. En principio, usamos fundamentalmente el concepto de masa descrito por Freud y Canetti, y nos cuestionamos si es suficiente para nuestra tarea o si realmente estaríamos enfrentando una coyuntura diferente donde el concepto de multitud, tal como lo formularon Hardt y Negri, sería más preciso para nuestra lectura. Como conclusión, constatamos que las manifestaciones sociales actuales tienen características mucho más cercanas a la topología de la multitud.

Palabras clave: masa, multitud, manifestaciones, topología. 


\section{FROM GROUP PSYCHOLOGY TO THE MULTITUDE: A NEW TOPOLOGY OF SOCIAL MANIFESTATIONS}

\begin{abstract}
This paper aims to make a political reading of the new forms of social manifestations by establishing a conceptual scope that allows us to understand, infer, and describe the topological structure of such political manifestations in contemporaneity. In principle, we fundamentally use the concept of group as described by Freud and Canetti, and we question whether it is sufficient for our task or
\end{abstract}

whether we are actually facing a different conjuncture where the concept of multitude, as formulated by Hardt and Negri, would be more accurate for our reading. As a conclusion, we confirm that current social manifestations have characteristics much closer to the topology of the multitude.

Keywords: group, multitude, manifestations, topology.

\section{DE LA PSYCHOLOGIE DES MASSES À LA MULTITUDE : UNE NOUVELLE TOPOLOGIE DES MANIFESTATIONS SOCIALES}

\section{Résumé}

Cet article vise à faire une lecture politique des nouvelles formes des manifestations sociales. Pour ce faire, nous établissons une approche conceptuelle permettant de comprendre, d'inférer et de décrire la structure topologique de ces manifestations politiques dans la contemporanéité. En principe, nous nous appuyons fondamentalement sur le concept de masse décrit par Freud et Canetti ; puis, nous nous demandons s'il est suffisant pour notre tâche ou si nous serions plutôt confrontés à une autre conjoncture, où le concept de multitude, tel que formulé par Hardt et Negri, serait plus précis pour notre lecture. En conclusion, nous avons constaté que les manifestations sociales actuelles ont des caractéristiques beaucoup plus proches de la topologie de la multitude.

Mots-clés : masse, multitude, manifestations, topologie. 


\section{Introdução}

Há algum tempo que a emergência de manifestações sociais contemporâneas vem surpreendendo o mundo, não só pelos efeitos políticos e sociais que desencadeiam, mas também pela forma singular como se organizam e encaminham seus funcionamentos e reivindicações. O efeito de surpresa se origina da constatação de que a lógica de organização e a topologia política e discursiva desses eventos parecem não se adequar às categorias políticas e sociológicas tradicionais, com as quais temos trabalhado no estudo e na pesquisa dos movimentos sociais, assim como no campo das relações entre política e processos de subjetivação, tornando-se assim, um curioso enigma a ser investigado.

Desde 2008 tais manifestações se intensificaram e recobrem o mundo em seus mais variados espaços e culturas, causando surpresa e interesse em melhor compreender quais seus fluxos, processos identificatórios e formas discursivas, mas, principalmente, suas consequências políticas e sociais. Elas ocorreram numa variedade geográfica espantosa, emergindo no mundo árabe - em países como o Irã, Tunísia, Egito, Líbia, Síria, Turquia (Castells, 2013) -, mas também no coração da Europa - na Espanha, Inglaterra - e ainda no núcleo mundial do capitalismo atual - Wall Street. Já em junho de 2013 foi a vez desse tipo de manifestação tomar de assalto as cidades brasileiras, constituindo verdadeiras "redes de indignação" (Castells, 2013) diante da ineficácia dos serviços públicos, do cinismo e corrupção da classe política.

Mesmo que antes de 2008 algumas formas de manifestações pontuais tenham se apresentado, foi a partir da crise econômica desse ano que afetou o mercado financeiro global e abalou as estruturas do então triunfante capitalismo informacional que tivemos o estopim de uma série de movimentos populares que também sinalizavam uma crise de legitimidade das estruturas políticas instituídas e da lógica cínica dos discursos que as sustentam (Castells, 2013). Muito provavelmente estamos vivenciando o esgotamento do que, após o fim do comunismo, Fukuyama (1992) chamou de "fim da história", assim 
entendido como o último estágio do exitoso liberalismo próprio do capitalismo global.

Então, podemos encontrar causas macroscópicas e globais para essas manifestações, mesmo que curiosamente não consigamos mapear suas reivindicações como parte de um amplo programa político de demandas públicas. Pelo contrário, "esses movimentos raramente são programáticos" (Castells, 2013, p. 169), o que determina "pequenas-causas" como o desencadeador da gênese das manifestações. Com exceção dos movimentos que ocorreram na denominada "primavera árabe" que lutavam diretamente pela mudança no poder instituído, outras manifestações mundiais caracterizam-se por uma mobilização em torno de reivindicações pontuais, por mais que daí possam encampar uma série de pontos que estejam na "pauta" política de uma determinada sociedade.

Encontramos esse funcionamento nas manifestações ocorridas no Brasil em junho de 2013. Mesmo tendo sido desencadeadas por reivindicações pontuais, a partir do "Movimento Passe Livre - São Paulo", e capitaneadas pela rejeição dos excessivos gastos com eventos esportivos - tais como a copa do mundo de 2014 e a olimpíada de 2016 - ficou razoavelmente claro que o descontentamento e incômodo dos manifestantes brasileiros fundava-se naqueles aspectos mais estruturais atrelados a novas formas de movimentos urbanos (Caste1ls, 2013; Rolnik, 2013).

Entendemos que a diversidade geográfica das manifestações resguardam suas peculiaridades políticas, históricas, discursivas, entre outras, já que, como dissemos, em alguns casos - como na denominada "primavera árabe" - observamos um direcionamento específico no sentido de um ataque direto e incisivo aos componentes do poder, o que por vezes resultou numa real derrubada - mesmo que, posteriormente, uma retomada deste poder tenha se realizado, não se definindo, portanto, na forma do que classicamente denominamos de "revolução". Consideramos, contudo, que há uma configuração comum - e, sem dúvida, levaremos em conta essas peculiaridades - já que essas mobilizações encerram uma série de características similares que talvez especifiquem as possibilidades de organização social 
não só geográficas, mas também o solo arqueo-genealógico de nossa época. A título de ilustração, citamos o fato que praticamente todas as manifestações utilizam-se das redes sociais - possibilitadas pelas novas tecnologias de informação e comunicação (NTIC) - como forma de organização e mobilização.

Considerando então esses amplos aspectos e a problematização de suas características estruturais é que entendemos tais manifestações como um fenômeno extremamente atual e singular. Por isso mesmo carecem de um esclarecimento teórico, político, ético, estético dos seus fluxos e formas, assim como dos processos internos que mobilizam seus membros e aglutinam demandas, identificações e reivindicações. Um certo número de autores já se lançaram numa tentativa de dizer algo sobre o assunto: Castells (2013), Hardt e Negri (2001; 2005), Žižek (2011; 2012; 2015), entre outros e iniciaram alguns esforços neste sentido.

No Brasil, após as manifestações de junho de 2013, alguns poucos se apresentaram numa tentativa de vislumbrar algum saber acerca desses fenômenos, entre eles, Birman (2014), Chaui (27 de junho de 2013), Viana (2013), mas nada que possa esgotar as possibilidades de problematização que os eventos comportam. A ainda incipiente produção sobre o tema certamente decorre da proximidade desses acontecimentos que não nos deram tempo hábil para promover um estudo científico minucioso.

Nosso objetivo primordial é realizar uma leitura política das manifestações sociais, estabelecendo um escopo conceitual que nos permita compreender, inferir e descrever a estrutura topológica das manifestações políticas na contemporaneidade, assim como os tipos de laço social que estabelecem, seja no ato propriamente dito das manifestações, seja nos laços estabelecidos via redes sociais. No momento, delimitamos nosso trabalho à discussão acerca desta topologia do poder no cerne da estrutura dessas manifestações, ou seja, se acompanham o modelo tradicional de "massa" descritos por Freud (2013/1921) e Canetti (1995) ou estariam muito mais próximas de uma lógica da "multidão", tal como formularam Hardt e Negri $(2001 ; 2005)$. 


\section{O Lugar das Redes Sociais}

As redes sociais caracterizam-se como um meio de possibilidades, que se erige através de elementos virtuais e de relações entre os usuários. Localizam-se naquilo que pode ser chamado de ciberespaço, no qual o crescimento é proporcionado pelas conexões entre computadores e celulares (Lévy, 1999). Nesse sentido, fundamentam-se não apenas através de pessoas ou grupos sociais, mas também através de uma série de dispositivos, gadgets e artefatos. Funcionam, portanto, através de uma inter-relação patente entre sistemas de objetos e pessoas (Santanella e Lemos, 2010). Nessa relação de compartilhamento de informações e conteúdos os sujeitos tornam-se fundamentalmente produtores e consumidores de informação (Torres, 2009).

A rede social, então, é uma comunidade não geográfica, uma estrutura essencialmente sem fronteiras (Marteleto, 2001), que representa uma ordem de participantes autônomos e possibilita um agrupamento de ideias e interesses compartilhados. Trata-se de uma forma de organização do trabalho informal, pois está presente na vida cotidiana dos sujeitos nos mais diversos níveis de estruturação das instituições modernas. Atualmente temos uma série de redes sociais em alta popularidade não só no mundo, mas também no Brasil. Elas se tornaram parte integrada da vida comum, locus onde se compartilha experiências cotidianas diariamente com familiares, amigos ou mesmo desconhecidos. Certamente o melhor exemplo é o Facebook, o Twitter e o Instagram.

Para nossa investigação interessa-nos algumas especificidades de estrutura e os aspectos dinâmicos dessas redes sociais. Para Recuero (2009) as redes sociais seriam uma espécie de metáfora que possibilitaria a observação de padrões de conexão de determinado grupo social. Por isso mesmo, seria possível observar como essas estruturas sociais surgem, de que tipo são, como são compostas através da comunicação proporcionada pelos gadgets e como tais interações têm o potencial de gerar fluxos de informação e trocas sociais que tragam impacto para suas estruturas. Logo, percebemos aqui como a dimensão política está atrelada à própria ideia de rede social. 
Como sabemos, é no próprio desenvolvimento em rede que acontece a maior parte das organizações, mobilizações e da socialização por partes dos indivíduos no mundo contemporâneo. Portanto, como confirma Marteleto (2001), são nesses espaços virtuais que se organizam a maior parte das ações políticas atuais. Esse novo cenário possibilita que os efeitos das redes possam ser percebidos fora daquele ambiente virtual, influenciando inclusive nas interações dos sujeitos com o Estado. A autora também esclarece que "nos espaços informais, as redes são iniciadas a partir de tomadas de consciência de uma comunidade de interesse e/ou de valores entre seus participantes" (p. 73).

As redes são orientadas por uma lógica associativa, ou seja, não supõem uma hierarquia, pois são definidas por sua multiplicidade, tanto quantitativa, como qualitativa no estabelecimento de seus laços. Porém, mesmo diante disso, não se exclui a existência das relações de poder nem "de dependência nas associações internas e nas relações com unidades externas" (Colonomos, 1995, pp. 22-24, citado por Marteleto, 2001, p. 73).

Através dos movimentos sociais e por meio da desaprovação das estruturas sociais vigentes é que vários tipos de ações coletivas têm levado os sujeitos a manifestarem suas insatisfações (Tavares e Paula, 2015). Esses movimentos se estabelecem por meio de redes de mobilização, onde são englobadas demandas e objetivos semelhantes compartilhados por manifestantes. Tais formas de ações coletivas acontecem através de revoltas populares e movimentos sociais, e são utilizadas em novos recursos e espaços que possibilitam a esses grupos se organizarem e agirem coletivamente através da articulação nas redes virtuais, possibilitando o aumento da amplitude da mobilização.

Um dos principais autores neste campo é Castells (1999), que considera que estamos diante de uma nova forma de sociedade: a sociedade em rede, que pode ser melhor observada se focarmos nossas análises na parcela da população que contém pessoas mais jovens. Tal camada é fortemente engajada dentro das redes sociais, 
tornando-se assim mais informada, mais escritora e mais leitora dos conteúdos veiculados no ciberespaço, o que os habilita a se comunicar de maneira muito mais eficiente se compararmos com as formas de comunicação disponíveis em épocas passadas.

É a partir dessa ótica que podemos abordar o fenômeno das manifestações sociais de junho de 2013 no Brasil. Podemos analisar tais movimentos que tiveram origem em mobilizações nas redes sociais como uma comunidade de prática com um grupo de pessoas que partilham dos mesmos interesses e criam laços entre si (Wenger, 1998). Lévy (1999) aponta para a dimensão política das redes sociais, entendendo a ascensão do ciberespaço como o resultado de um verdadeiro movimento social, tendo como motor uma juventude metropolitana escolarizada que trabalha em rede através da disseminação de informações.

A sociedade em rede não pode ser associada apenas a um desaparecimento da interação face a face com o outro ou como um mecanismo que promove o afastamento do indivíduo com o objeto real, já que ela também tem a capacidade de expandir relações. Desde que usada numa determinada forma e escala, pode permitir aos usuários uma possível expansão das suas relações sociais, ou mesmo uma passagem da realidade virtual para a real. Portanto, é necessário ultrapassar esse obstáculo ou mesmo este preconceito para com as redes sociais que ressalta fundamentalmente seus efeitos negativos. Nesse sentido, Castells (1999) define a sociedade em rede como uma sociedade "hipersocial".

O isolamento social, que diversas vezes é associado ao uso da tecnologia, não é causado somente pela "sociedade em rede", mas também pela lógica proveniente das redes de comunicação, bem como os deslocamentos da estrutura social e da evolução histórica como um todo. Tal cenário induz a necessidade de isolamento, ou seja, a uma facilidade de selecionar os contatos sociais, proporcionando uma agilidade de início e término de interação com o outro (Castells e Cardoso, 2005, p. 23). 
Segundo Castells (1999) os movimentos oriundos das redes sociais são um sintoma de uma falha na lógica da atual democracia representativa, pois o que se observa são partidos políticos motivados por seus próprios interesses. Assim, é por meio das redes sociais que é possível subtrair a impotência diante dessa falta de veto dos cidadãos perante decisões tomadas por seus representantes políticos, não limitando a voz do povo apenas ao poder de voto a cada quatro anos. O uso do potencial tecnológico aliado a informação permite a população reivindicar uma melhor qualidade de vida, assim como o direito à educação, saúde, transporte de qualidade entre outros interesses.

Independente de suas motivações, na maioria das vezes a participação em redes sociais envolverá responsabilidades, direitos e tomadas de decisões. Segundo Colonomos (1995) não necessariamente haverá uma organização vertical, pois poderá ser orientada pelos elos formados entre os membros. No entanto, sua organização horizontal não excluirá as relações de poder e dependência nas associações internas e externas mantidas pelas redes sociais.

Este sem dúvida é um dos aspectos estruturais das manifestações que nos interessa diretamente, já que em nossa abordagem buscaremos estabelecer uma lógica discursiva da topologia das relações de poder no cerne dessas mobilizações. Partimos de uma questão inicial: estaria essa topologia de acordo com uma lógica das "massas" que, segundo autores fundamentais, como Freud (2013/1921) e Canetti (1995), entre outros, a situaram dentro de uma lógica de poder vertical, orbitando em torno da figura de um líder, ou, pelo contrário, organizar-se-iam horizontalmente, dissolvendo os lugares fixos e estabelecendo uma topologia política cuja função decisória seria realmente democrática, muito mais próxima do que Hardt e Negri (2001; 2005) denominaram de "multidão"? Se assim o for, estaríamos, então, diante de uma nova modalidade de reivindicação social, que não mais acompanharia o modelo dos tradicionais movimentos sociais? Quais as consequências políticas e sociais dessa suposta nova forma de reivindicação social? Por enquanto, deixemos essas como questões disparadoras do nosso trabalho. 


\section{Da psicologia das massas à multidão}

A discussão sobre os fenômenos de massa ou das multidões já se tornou clássica nos campos da sociologia e da psicologia social, mas também está presente nos estudos psicanalíticos, embora de forma singular. A obra de Marx já comporta um estudo sobre as manifestações sociais e uma proposta política de encaminhamento desses movimentos. Entretanto, é a partir do trabalho de Le Bon (1963/1895) sobre a "Psicologia das Multidões", datado do ano de 1895, que se inicia uma série de investigações sobre a lógica e a topologia interna das massas. Esse estudo acabou influenciando os trabalhos posteriores do campo da sociologia e da psicologia social.

O tema fora retomado por Freud (2013/1921) em seu célebre "Psicologia das Massas e Análise do Eu", que estabeleceu seus processos internos, muito especialmente os de identificação, assim como descreveu a "economia libidinal" própria das massas. Daí por diante o tema tornou-se crucial para os estudos sociais, transpassando os trabalhos da "Escola de Frankfurt", entre outros. Contudo, certamente uma das obras mais significativas sobre o tema é o extenso trabalho de Canetti (1995), "Massa e Poder", que realiza um contraponto fenomenológico ao trabalho de Freud e amplia o debate para seu espaço antropológico. O presente debate mais recentemente ganhou mais um capítulo com os trabalhos de Hardt e Negri $(2001 ; 2005)$ que realizaram uma leitura das formas de organização política atuais, situando-as nas condições de possibilidade do mundo contemporâneo.

Não podemos desconsiderar, por exemplo, que esses fenômenos atuais estejam inseridos e determinados - mesmo que não completamente, já que o "acaso" e o "inesperado" devam ser apreciados pela revolução cibernética e tecnológica que geram rearranjos sociais (Caiaffo et al., 2007), estabelecem novos laços sociais em rede, e criam outras subjetividades. Todo esse quadro deve se situar, ainda, no conjunto do processo contemporâneo de capitalização global, cujas dimensões sócio-políticas e subjetivantes foram muito bem descritas e analisadas por Hardt e Negri (2001), que as definem de maneira incisiva como "Império". 
Partimos do pressuposto, portanto, de que as atuais manifestações não se enquadram no que classicamente definiu-se como os fenômenos de "massa", pois estariam muito mais próximas em suas formas e lógica de funcionamento daquilo que Hardt e Negri (2001; 2005) denominaram de "Multidão". No entanto, qual afinal seria a distinção crucial entre massa e multidão? Quais as consequências políticas e de subjetivação dessas distinções?

\section{A massa em Freud}

O surgimento dos primeiros estudos sobre as formações de massa no século XIX decorrem certamente do desenvolvimento arqueo-genealógico da sociedade moderna industrial e capitalista, muito especialmente do caráter industrial-disciplinar (Foucault, 1977) com o qual as relações sociais e as relações de poder se estabelecem neste período, subsidiados pela progressão do discurso científico e seus efeitos. Não por acaso, observariamos no século seguinte, dois dos maiores fenômenos de massa da modernidade: o comunismo e o nazismo. Ambos referidos aos processos discursivos em marcha: o primeiro como uma reação à exploração capitalista, e o segundo como uma fusão e aplicação do discurso científico - uma genética bio-política delirante (Foucault, 1988) - à gestão política da cultura.

A consequente constituição de uma classe operária-proletária determinou a emergência originária de alguns movimentos sociais - como o início das organizações sindicais - muito próprios do que tradicionalmente se denomina de "modernidade". A obra de Marx (1982) é certamente o maior e melhor diagnóstico político dos movimentos sócio-políticos e econômicos deste período e do desenvolvimento do capitalismo industrial subsequente.

Entretanto, coube a Le Bon (1963/1895) introduzir na leitura dos fenômenos de massa uma discussão preocupada com o caráter psicológico desses movimentos, tendo inclusive correlacionado suas emergências com uma crise da sociedade moderna. Para o autor a multidão se organizaria em torno da fusão dos indivíduos de sentimentos e 
ações comuns, de uma forma irracional, o que indicava a necessidade de um líder.

A personalidade consciente desaparece, os sentimentos e as idéias são orientados numa mesma direção. Forma-se uma alma coletiva, transitória sem dúvida, mas apresentando caracteres muito claros. A coletividade torna-se, então, o que, na falta de uma expressão melhor, chamarei de foule organizada, ou se se preferir, uma foule psicológica. Ela forma um só ser e se encontra submissa à lei de unidade das foules. (Le Bon, 1985/1963, p. 9).

Sabemos que o referido conceito em Le Bon não se estabelece de uma forma homogênea, apresentando-se como um conceito muito próprio de um autor fincado numa posição conservadora dos movimentos populares. Como esclarece Consolin (2004),

...o conceito de "multidão" é, pois, um termo genérico e carregado de imprecisões, mas que não obstante se tornou um instrumento que permitiu mobilizar um arsenal de críticas (e de grandes sínteses) contra as classes populares, as instituições da Terceira República, as elites políticas e intelectuais da época e, finalmente, o desempenho econômico e político da França no cenário internacional. (p. 2).

Freud (2013/1921), por sua vez, busca determinar a lógica dos mecanismos internos e inconscientes próprios da "massa" e, neste intuito, mantém uma concepção tradicional do fenômeno. Isso certamente está vinculado ao fato de Freud estar situado num período entre guerras, o que se apresenta em seu texto, pois questiona o que teria levado a humanidade à tamanha barbárie, destruição e violência.

De todo modo, Freud (2013/1921) vai além das proposições de Le Bon, estabelecendo uma correlação entre a psicologia individual e a psicologia social. A dissolução dos limites entre a psicologia social e a individual - dissolução já "canônica" para o campo da psicanálise - determina toda uma lógica que vai permitir à Freud sua abordagem singular da massa (p. 11). É essa outra abordagem não dualista que possibilita a descrição dos mecanismos de identificação e os investimentos libidinais dos grupos, assim como uma topologia da aliena- 
ção dos indivíduos através da figura do líder. Discorre, ainda, sobre os mecanismos da formação dos grupos, a lógica de funcionamento do amor, o ciúme, a submissão cega das massas a um líder, assim como a intolerância à diferença.

As massas se alienariam orbitando em torno do lugar do líder; lugar este que compara ao lugar de um "pai substituto" (Freud, 2013/1921, p. 120). Esse processo se dá fundamentalmente através do processo de identificação, que Freud reconhece como uma das manifestações mais antigas de uma ligação afetiva a outra pessoa (p. 33). A coesão da massa se estabeleceria exatamente por esses processos identificatórios e libidinais que envolveriam a função narcísica do "Eu" na busca de uma aproximação com seus ideais (p. 62). Entretanto, isto não se faz sem consequências: inserido na massa o indivíduo experiencia uma série de efeitos, como o aumento de sua afetividade, a diminuição de sua capacidade intelectual, auferidos por conta deste nivelamento identificatório com os demais.

As massas se estabeleceriam em sua homogeneidade mental, produzindo efeitos de alienação, de recalcamento e, portanto, de sintoma. Essa universalização, na forma de uma Weltanschaüung (Freud, 1976/1933) faria perder o traço de singularidade do sujeito, que só poderia se manifestar sintomatologicamente.

Para Freud basta dizer que na massa o indivíduo está sujeito a condições que lhes permitem se livrar das repressões dos seus impulsos pulsionais inconscientes. Nestas condições, o indivíduo abriria mão de uma condição narcísica e de uma satisfação individual em prol de uma coletividade. Sua condição na massa, então, seria comparável a de um autômato, onde em um estado hipnótico o sujeito ficaria suscetível à qualquer tipo de influência. Tornar-se-ia, assim, um ser acrítico, influenciável e crédulo (Freud, 2013/1921).

Como a massa não tem dúvida quanto ao que é verdadeiro ou falso, e tem consciência de sua enorme força, ela é, ao mesmo tempo, intolerante e crente na autoridade. Ela respeita a força, e deixa-se influenciar apenas moderadamente pela bondade, que para ela é uma espécie de fraqueza. O que ela exige de seus heróis é fortaleza, até mesmo 
violência: quer ser dominada e oprimida, quer temer os seus senhores. No fundo, inteiramente conservadora, tem profunda aversão a todos os progressos e inovações, e ilimitada reverência pela tradição.

Freud (2013/1921) chega a afirmar que as massas nunca tiveram a sede da verdade, pois preferem as ilusões, às quais não podem renunciar. Nelas o irreal tem primazia sobre o real, o que não é verdadeiro as influencia quase tão fortemente quanto o verdadeiro, já que têm a visível tendência de não fazer distinção entre ambos.

Contudo, o que se sobressai nas formações de massa é o caráter de imaginarização, de homogeneização mental, de perda da singularidade. Nessa condição hipnótica da massa, "o objeto, nos diz Freud, foi colocado no lugar do "Ideal do Eu" (Freud, 2013/1921, p. 144), produzindo uma identificação com o líder. Como "herdeiro do narcisismo originário" (p. 138) o "Ideal do Eu" é o que sustenta uma identificação a partir de uma perda do objeto. A submissão do sujeito ao líder implica nessa operação inconsciente onde o líder ocupa o lugar do ideal, produzindo uma injunção narcísica e, portanto, a identificação grupal.

Para ilustrar suas hipóteses Freud (2013/1921, p. 46) diferencia algumas modalidades de massa segundo a sua formação: massas passageiras e massas duradouras, massas homogêneas, que se compõem de indivíduos do mesmo tipo, e não homogêneas; naturais e artificiais, isto é que requerem também uma coação externa para se manter. A partir daí passa a analisar duas massas que considera como "massas artificiais", o exército e a igreja.

Nestas há uma coação externa utilizada para evitar sua dissolução e impedir mudanças, além de também estar presente a ideia da manutenção de uma ilusão no líder. O laço entre os membros depende dessa ilusão; se ela fosse abandonada, imediatamente a massa se dissolveria, já que os membros das massas artificiais manteriam uma dupla ligação libidinal: uma com o líder e outra com os outros indivíduos da massa. Produziriam ainda uma espécie de apagamento do sujeito como efeito da promessa de um amor incondicional do líder, oferecido por uma fraternidade de irmãos, na qual todos gozariam dos mesmos direitos (Freud, 2013/1921). 
Para que essa lógica funcione cria-se uma cumplicidade sintomática entre os indivíduos. É necessário que o líder passe a ocupar o lugar do "Ideal do Eu", produzindo seus efeitos de identificação, mas também efeitos de hipnose grupal e de ambivalência. O indivíduo identifica seu "ideal do eu" com um "ideal do grupo" personificado no líder, submetendo-se aos efeitos de sugestão e de identificação (Freud, 2013/1921, p. 67).

Esse lugar do líder - e é importante tomá-lo como um lugar, já que pode ser substituído por uma idéia dominante - precisa responder a uma questão narcísica do sujeito já que ele abdicou de sua singularidade. Há uma verdadeira "afânise" (Lacan, 1988/1964) do sujeito nessa condição de alienação na massa. Essa resposta se dá na forma de uma "consistência imaginária" (Lacan, 2002/1974-75) na identificação com o semelhante. Ser igual aos outros tem toda uma importância identificatória para ao sujeito na relação com a imagem do outro.

\section{A Concepção de Massa de Canetti}

Na obra intitulada "Massa e Poder", Canetti (1995) nos permite refletir um pouco mais sobre essa personificação do líder como uma forma de direcionar a massa.

O autor apresenta uma argumentação axiomática que será basilar para os desdobramentos que seguem seu trabalho. Numa perspectiva mais fenomenológica, parte da suposição de que o que mais amedronta é o medo do desconhecido. O medo do contato com o desconhecido representa uma defesa que gera um distanciamento com aquilo que causa tal sentimento. Nunca temos a certeza absoluta do que o outro quer, mesmo com aqueles que consideramos mais íntimos. No entanto, há um momento em que a diluição desse temor pode se estabelecer. Esse estado ocorre quando os sujeitos se submetem ao fenômeno da massa, que é justamente resultado da inversão do temor do contato (p. 13). 
Assim, no fenômeno da massa, ocorreria uma inversão do temor do contato, já que o sujeito acha-se convocado à deixar de lado o medo do desconhecido (p. 14). A massa proporcionaria uma sensação de segurança junto àqueles que a compõe, deixando as individualidades causadoras de segregação em segundo plano. O sentimento de igualdade, então, produz e sustenta um estado de unidade.

A partir daí Canetti (1995) estabelece uma fenomenologia das massas, definindo-as estruturalmente em subdivisões. Numa primeira oposição descreve as "massas abertas" ou "massas naturais" (p. 14). A abertura aqui diz respeito à sua expansão. Ela sempre quer crescer, abarcar idealmente um todo. Sua constituição é rápida, mas por outro lado, o seu desfecho também é. Em oposição temos a "massa fechada", cujo crescimento é determinado, não sendo possível extrapolar a quantidade de pessoas predefinidas. Por ser mais seletiva, acaba por se tornar mais consistente e consequentemente mais duradoura.

Uma característica que podemos retirar da concepção de Canetti (1995) é que a massa é uma espécie de corpo vivo que apresenta certas características. Dentre elas existem certos acontecimentos como os que denominou de "erupção" (p. 20) e "sentimento de perseguição" (p. 23). O primeiro faz referência à demanda que a massa tem de sempre querer se expandir. Isso quer dizer que toda massa, por mais peculiar que possa ser, deseja se tornar "massa aberta". E é razoável que esse fenômeno ocorra periodicamente.

Sucksdorf (2011), no livro intitulado "Del temor a ser tocado: massa y subjetividad" propõe discutir os fenômenos de massa e sua relação com a subjetividade, ou seja, como se constrói um laço onde o "eu" está contido em um "nós". Para fazer esse estudo o autor utilizou como base teórica um cotejamento entre as obras de Freud e Canetti.

Sendo assim, o autor parte das proposições de Canetti acerca do temor do contato com o desconhecido, bem como da questão de que só é possível o movimento de massa caso ocorra a inversão deste temor. Essas duas proposições são basilares na construção de seu trabalho 
que irá culminar em uma produção bem extensa e bastante descritiva sobre as várias possibilidades de constituição desses movimentos.

Ao apresentar as ideias de Freud, no que é capaz de unir as massas, Sucksdorf (2011) destaca a questão da função do amor na constituição deste laço, como é observável na formação das massas artificiais em seus laços transferenciais com a figura de um líder. Será então através da libido e do laço afetivo criado a partir desta que se conseguiria manter unidos esses indivíduos com diferenças entre si, principalmente pela figura visível ou invisível do líder. Isto tornaria a massa mais forte e densa, difícil de se desfazer, tal como referidos por Freud nos exemplos das igrejas e do exército (p. 13).

Sucksdorf (2011) acompanha a crítica de Canetti ao texto da "Psicologia das Massas e análise do eu", que tomou como seu anti-modelo. Tal crítica visa uma posição "externa" de Freud com relação ao fenômeno das massas, inviabilizando assim um melhor entendimento descritivo das peculiaridades concernentes aos próprios movimentos, ou seja, Freud teria produzido suas conclusões a partir do lado de fora do fenômeno e não de dentro do mesmo.

Interessa-nos particularmente a definição canettiana de "massas espontâneas" e o desenvolvimento dado ao tema por Suksdorf (2011), pois nos parece ser o "tipo" de massa que mais se aproxima das manifestações contemporâneas. Trata-se de massas que surgem espontaneamente e são sempre abertas, ou seja, não possuem uma unidade de força e orientação forte como as massas fechadas das quais temos como exemplo o exército.

Para Sucksdorf (2011), essa instabilidade em manter-se unida é determinada pela sua lógica de formação, já que muitas vezes são formadas por indivíduos que nem sempre possuem os mesmos objetivos, além de crescerem em uma grande velocidade e com certa desorganização.

Diante disso é possível supor que a instabilidade das "manifestações" atuais e suas rápidas dissoluções seriam um indício da falta de uma consistência determinada pela ausência de um líder? Talvez 
seja uma afirmação muito rápida. Antes disso precisamos investigar a lógica de funcionamento discursivo e político das manifestações, para que não incorramos numa interpretação apressada, por seguir unicamente o modelo freudiano da massa. Pois como salienta Sucksdorf (2011), isto pode também significar "que una identificácion puede darse sin la necesidad de lazo libidinal originariamente horizontal" (p. 27).

Esta breve caracterização das várias concepções da "massa" servem para que possamos interrogar e cotejar seu funcionamento e estrutura com a que viermos a constatar na lógica das manifestações. Obviamente que partimos do pressuposto de que as "manifestações contemporâneas" não acompanham diretamente a forma das massas. Pelo contrário, apresentam uma originalidade que devemos observar, interrogar e desenvolver em nosso trabalho. Não estamos impedidos, contudo, de constatar uma relativização desta suposição, ou mesmo, em encontrar características das formações da massa na lógica de funcionamento nas manifestações.

Entretanto, sabemos que não podemos nos resumir a uma constatação fenomenológica das formas de funcionamento desses eventos. Precisamos situá-los nos deslocamentos arqueo-genealógicos, retirando deles uma possível explicação conceitual e política que nos ajude a pensar e trabalhar com o que supomos ser uma nova topologia das manifestações políticas e sociais do mundo contemporâneo.

O que nos interessa também é, a partir desta "topologia das massas" descrita por Freud e Le Bon cuja característica primordial é orbitar em torno da figura do líder, assim como da descrição fenomenológica dos tipos de massa de Canetti, e interrogar se esta "topos-lógica" se mantém na forma de funcionamento das manifestações atuais. Obviamente que partimos da suposição - como já insinuamos acima - que uma outra topologia se encena em nossos tempos, afetada pelos movimentos arqueo-genealógicos fundados desde a abertura da modernidade e intensificados pela lógica pós-moderna e sua outra relação "topolítica" com a linguagem e com o lugar do Outro (A). 
Apenas para concluir, podemos constatar que a noção de massa fora gestada num espaço e tempo arqueo-genealógicos de gênese da modernidade, onde também observávamos a aurora da instalação dos discursos científicos e dos efeitos de "desterritorialização" (Deleuze e Guattari, 1976) das movimentações do capitalismo. Vivíamos um tempo imediatamente posterior ao fim da soberania (Foucault, 1977) e, portanto, de esvaziamento dos espaços de transcendência. A "imanentização" histórica do mundo estava por se fazer, por isso o espaço topológico do líder ainda se manifestava de uma forma incisiva na formação das massas.

\section{Da Massa à Multidão}

Estamos hoje num outro momento arqueogenealógico. Dos tempos da gênese da modernidade para os dias atuais, o que observamos foi todo um processo cultural, histórico, político e discursivo que culminou com o que se denomina hoje de pós-modernidade, ou contemporaneidade. Não estamos mais numa cultura industrial-disciplinar. $\mathrm{O}$ diagnóstico de Deleuze (1992) fora preciso: vivemos numa "sociedade do controle", quando a disciplina já se instalou de forma imanente na cultura, mas também cujos espaços de transcendência se dissolveram, inclusive os da estrutura de linguagem, produzindo um efeito de imanentização (Lebrun, 2008) dos espaços de exceção.

A "multidão", tal como definida por Hardt e Negri (2005) é uma formação muito própria de um tempo para o qual a soberania já não diz muito, e por isso mesmo sua topologia e processos identificatórios e discursivos não se referem diretamente nem a um líder, nem tampouco à um ideal cultural normativo comum à lógica da soberania. Diferentemente da "massa" e do "povo", a multidão não é "una"; ela é "composta de um conjunto de singularidades" (p. 139), que contrastam com a "unidade indiferenciada do povo" (p. 139). Podemos dizer, portanto, que a multidão é uma formação social própria de uma sociedade em rede, caracterizada não mais pela dominância da lógica disciplinar, mas pelos mecanismos de controle que implicam o triunfo do capitalismo global e as novas tecnologias. 
Na lógica da sociedade de controle os mecanismos de inclusão e exclusão não estão mais apenas nas instituições, eles agora estão nas pessoas, interiorizados nos indivíduos, onde eles normatizam a si mesmos. Logo, o poder é exercido por máquinas que organizam tanto os corpos, sistemas de bem-estar e atividades monitoradas, bem como os cérebros e as redes de comunicação e informação (Hardt \& Negri, 2001). O objetivo de se controlar corpos e cérebros é promover um "estado de alienação independente do sentido da vida e do desejo de criatividade", fazendo com que os mecanismos de poder assumam uma estrutura mais flutuante e flexível, já que estão por toda a parte (Hardt \& Negri, 2001).

Com essa mudança na estrutura de exercer o poder houve um "definhamento" da sociedade civil. As instituições sociais que compunham a sociedade disciplinar passaram por uma crise (Hardt \& Negri, 2001), de maneira que a "queda" das instituições e o declínio da sociedade disciplinar promovem o surgimento das redes da sociedade de controle.

Assim, a transição para a sociedade do controle determina a produção de subjetividades mais flexíveis, não fixadas em identidade, "subjetividades híbridas e moduladas" (Hardt \& Negri, 2005, que não se prendem a nenhum vínculo identitário, mas sim com todos os vínculos, conforme a lógica "do capital". Trata-se de uma nova forma de existir, mais flexível e mutável e, consequentemente, mais fragmentada. Esse novo tipo de configuração da subjetividade aparece dando condições para que os indivíduos assumam diferentes papéis sociais e fazendo inúmeras atividades, em contextos diferentes, com o objetivo de executar tarefas com maior complexidade e voltadas para a criação, comunicação e contatos sociais (Mansano, 2011). Assim, os indivíduos não ficam mais reduzidos a uma só identidade conhecida e cristalizada, ocupando um papel social uno. Por isso mesmo são subjetividades cujas reivindicações se manifestam em formas horizontalizadas, através de redes sociais.

Decorre daí a desconstrução estabelecida do conceito de povo. Para Hardt e Negri (2005) o conceito de povo já não se sustenta mais, 
assim como a identidade é substituída pela mobilidade, flexibilidade e perpétua diferenciação da massa. Com isso, destitui-se a ideia, muito própria do conceito de povo descrita pelo autores, de um poder que se constrói a partir da figura de um único sujeito - líder. Por isso mesmo que propõem a lógica da "multidão" como um novo conceito que tenta explicar a forma de movimentos sociais hoje.

Se historicamente podemos pensar a forma de se governar como uma democracia que é baseada em um corpo político unificado dotado de órgãos e membros os quais dão uma sustentação ao governo, a multidão quebra esse paradigma ao propor uma nova maneira de se governar. Ao mesmo tempo em que é multiplicidade e diversidade, age em prol de um bem comum.

Carvalho (2017) diz que o conceito de multidão se difere do conceito de povo, massa e classe trabalhadora, já que os sujeitos sociais são outros. A autora observa que a multidão é conceituada como grupo proletário e revolucionário que consegue organizar as singularidades. Dessa forma, esse grupo é formado por inúmeras diferenças internas, onde as singularidades não são e nem podem ser reduzidas a uma única forma identitária. Para a autora o desafio da multidão é se comunicar e agir de forma comum, mesmo mantendo as diferenças. Ou seja, a multidão deve conseguir descobrir o comum que habita em todos, e apesar das diferenças que compõe o grupo, poder se comunicar e agir como um, sendo múltiplos.

Para Carvalho (2017) a multidão proposta por Hardt e Negri vem propor a ideia de uma nova democracia, e para tal é necessário atentar para dois requisitos: o comum, ou seja, o que mantém o grupo produzindo e compartilhando entre si, já que esse comum se expande enquanto produção biopolítica; e o desejo de democracia, pois esse desejo é o que mantém viva as lutas e movimentos sociais de libertação ao redor do mundo. Quando a autora fala em "nova democracia", ela entende que Hardt e Negri anunciam o fim da democracia enquanto representativa e também a formação de um governo de todos por todos, e acreditam na multidão como uma revolução pós-moderna, na qual ela conseguirá mudar a sociedade autonomamente. 
Dessa forma, Carvalho (2017) observa que o político é relatado como sendo o reino da colaboração e da comunicação, e que a produção do sentido de comum tende a borrar as barreiras definidas entre o público e o privado. Porém, a teoria do comum, bem como o princípio da comunalidade, abordados por Hardt e Negri, não chegariam a explicar mais amplamente a multidão no sentido de uma organização política, abordando apenas a fenomenologia dos movimentos sociais. Assim, o conceito de multidão fica como sendo uma narrativa, que produz singularidades e uma nova linguagem discursiva.

De todo modo, para Hardt e Negri (2005) a multidão é o único sujeito social capaz de realizar a democracia, ou seja, o governo de todos por todos, pois seria o único sujeito social na atualidade capaz de promover uma emancipação dando voz às diversas singularidades, sejam elas de gênero, de raça, ou mesmo de classe. Ela - a multidão - teria uma tendência a superar o império sem necessidade de articulação política alguma, ou seja, o que for referente a estratégias políticas desapareceria. Não podemos deixar de denunciar a ingenuidade da concepção "apoliticista" dos autores, que Carvalho (2017) considera como uma visão empobrecida do cenário político, já que as polaridades de poder são bem visíveis e as estratégias continuam sendo importantes.

O recorte que nos interessa dessa concepção, além do seu caráter fenomenológico e descritivos dos atuais manifestações sociais, é sua definição como um grupo de pessoas reunidas para um determinado fim (Hardt e Negri, 2001; 2005). Não há na multidão um líder à quem se deva obediência e submissão, nem tampouco um poder e uma identificação vertical.

\section{Considerações finais}

Como conclusão podemos assinalar que as manifestações ocorridas no Brasil em junho de 2013 apresentaram uma topologia única, cujas características diferenciam-se do que tradicionalmente se considera uma "massa". Essa é uma constatação no mínimo embaraçosa, pois 
impõe em certo sentido a necessidade de um novo regime de interpretação que considere e admita que a lógica até então vigente não consegue dar conta totalmente dos atuais fenômenos de organização social e política.

É possível observar nessas manifestações a ausência patente do tradicional lugar de líder, assim como de um poder verticalizado. Com isso, nos deparamos com uma intensificação das singularidades e das reivindicações contingentes, o que proporcionou a emergência de um poder de caráter horizontalizado e com aspectos ditos democráticos. Democrático aqui pode ser entendido como a ideia extremamente difundida durante as manifestações de que as decisões concernentes às mesmas só poderiam ser decididas em conjunto, pelos que estavam presentes, como se o povo fosse o líder.

Outra característica das manifestações foi sua organização através do uso das redes sociais. Nesse tipo de engajamento não há um processo histórico de passado, presente e futuro, mas somente a ideia do evento pontual, onde sustenta-se a concepção de que basta um clique para participar e promover mudanças sociais concretas no seio da sociedade.

Além disso, as redes sociais parecem guardar relações patentes com a topologia encontrada nas manifestações de junho de 2013 no Brasil, posto que tais espaços virtuais são orientadas por uma lógica associativa que não trabalha com uma perspectiva hierárquica, mas estabelece conexões através de uma orientação voltada para o campo da multiplicidade quantitativa e qualitativa dos laços. Portanto, o que vemos novamente aqui é a assunção de um modelo de relações que considere a horizontalidade como um valor essencial.

Prosseguindo em nossas conclusões podemos dizer que a massa é uma formação social própria de uma sociedade moderna, pós-soberana, dos primórdios de uma dispersão discursiva que pode ser exemplificada pelo "Deus está morto" (Nietzsche, 2001), e que nem por isso extinguiu o "desamparo infantil" (Freud, 2010/1930), cujos efeitos são o de tentar reposicionar um líder no lugar soberano-transcendente que se esvaziou na passagem do diagrama soberano 
ao disciplinar (Foucault, 1977), utilizando-o como polo identificatório unificador. Os esforços de Freud, portanto, não foram em vão, mas poderíamos dizer que não nos servem completamente para balizar conceitualmente os fenômenos atuais das manifestações.

Isto posto, as manifestações de junho de 2013 ocorridas no Brasil estariam topologicamente muito mais próximas daquilo que Hardt e Negri (2005) chamaram de multidão, que na visão dos autores seria uma espécie de organização social composta por um conjunto de singularidades onde a lógica disciplinar cai por terra e há a ascensão de um modelo de sociedade sustentado em rede.

Contudo, talvez essa primeira constatação nos imponha um outro possível debate acerca do caráter emancipatório dessas manifestações, o que, longe de fechar uma discussão, abre um questionamento: poderíamos mesmo concordar com o que afirmam categoricamente Hardt e Negri (2005), de que "a ação política voltada para a transformação e a libertação só pode ser conduzida hoje com base na multidão" (p. 139)? Ou deveríamos escutar as considerações de Žižek (2011), para quem Hardt e Negri pecariam por uma ingenuidade paradoxal, já que a ideia que promovem, a partir da concepção de multidão, habitaria o cerne mesmo do capitalismo contemporâneo?

Levando em consideração essa questão podemos assinalar que as manifestações de junho de 2013 na verdade não conseguiram promover mudanças políticas concretas no interior das nossas questões mais urgentes.

Sobre isso é possível que a generalidade e a heterogeneidade dos grupos e das pautas reivindicatórias apresentadas determinaram a forma, a potência e a continuidade das manifestações. A diversidade dos grupos causou dificuldade nas articulações em comum com as demandas da sociedade, impossibilitando a construção de uma "coesão" no núcleo da massa (Canetti, 1995). Dizemos isso por saber que na evolução das manifestações estes grupos foram incapazes de se manter unidos e coesos, assim como de constituir "mobilizações sociais" permanentes. 
Assim, na falta de uma coesão geral, os lugares específicos se apresentavam de forma embaralhada: líderes, porta-vozes, "bodes expiatórios", etc. - para utilizar a clássica diferenciação de Pichon-Rivière (1988) - alternavam-se de forma indefinida e ao sabor dos acontecimentos.

Esse cenário de progressiva apatia pode ter se consolidado por conta da ausência de uma liderança concreta, o que nos dá mais elementos para questionar o poder emancipatório radical de organizações sociais formadas a partir da lógica da multidão. Abre-se, então, a questão se essas manifestações, fundadas nessa nova topologia, marcariam definitivamente as formas de reivindicações política e social daqui por diante. Estaríamos diante de uma nova forma de reivindicação, ou pelo contrário, constatando uma dispersão do caráter político e emancipatório dos movimentos sociais?

\section{Referências}

Birman, J. (2014). O sujeito da diferença e a multidão. Ide, 36(57), 25-40.

Caiaffo, S., Silva, R., Macerata, I., \& Pilz, C. (2007). Da multidão-massa à multidão-potência: contribuições ao estudo da multidão para a Psicologia Social. Arquivos Brasileiros de Psicologia, 59(1), 01-12.

Canetti, E. (1995). Massa e poder. Companhia das Letras.

Carvalho, F. L. (2017). Política como construção do povo versus o fenômeno das multidões como a morte política: as perspectivas teóricas de Laclau e Negri. In Observatório Político (Documento de trabalho no. 72, pp. 1-18). http://www.observatoriopolitico.pt/wp-content/uploads/2017/06/ WP_72_FLC.pdf.

Castells, M. (1999). A era da informação: economia, sociedade e cultura, Vol. 1. A Sociedade em Rede. Paz e Terra.

Castells, M. (2013). Redes de indignação e esperança: movimentos sociais na era da internet. Zahar.

Castells, M. e Cardoso, G. (Orgs.). (2005). A Sociedade em Rede: do conhecimento à ação política: Conferência. Imprensa Nacional.

Chauí, M. (27 de junho de 2013). As Manifestações de junho de 2013 na cidade de São Paulo. Teoria e Debate, 113. http://www.teoriaedebate.org.br/ 
materias/nacional/manifestacoes-de-junho-de-2013-na-cidade-de-saopaulo?page=full.

Colonomos, A. (1995). Sociologie des rèsseaux transnationaux; communautés, entreprises et individus: lien social et système international. L'harmattan.

Consolin, M. C. (6 a 10 de setembro de 2004). Gustave Le Bon e a reação conservadora às Multidões. In Anais do XVII Encontro Regional de História. O lugar da História. ANPUH/SPUNICAMP, Campinas, Brasil.

Deleuze, G. e Guattari, F. (1976). O anti-édipo - capitalismo e esquizofrenia. Imago.

Deleuze, G. (1992). Post-Scriptum sobre a sociedade de controle. In Conversações, 34. https://edisciplinas.usp.br/pluginfile.php/81001/ mod_resource/content/1/TC\%20Post $\% 20$ scriptum $\% 20$ sobre $\% 20$ as $\% 20$ sociedades $\% 20 \mathrm{de} \% 20$ controle.pdf.

Foucault, M. (1977). Vigiar e Punir. Vozes.

Foucault, M. (1988). A história da sexualidade, Vol. I. A vontade de saber. Graal.

Freud, S. (1976/1933). Novas conferências introdutórias a psicanálise. Conferência XXXV - A questão de uma Weltanschaüung. In Edição standard brasileira das obras completas de Sigmund Freud (Vol. XXII, pp. 193-220). Imago.

Freud, S. (2010/1930). O mal-estar na civilização. In Paulo César de Souza (Trad.), Obras Completas (Vol. 18, pp. xx-xx). Companhia das Letras.

Freud, S. (2013/1921). Psicologia das massas e análise do eu. In Paulo César de Souza (Trad.), Obras completas (Vol. 15, pp. 13-113). Companhia das Letras.

Fukuyama, F. (1992). O fim da história e o último homem. Rocco.

Hardt, M. \& Negri, A. (2001). Império (Clovis Marques, Trad.). Record.

Hardt, M. \& Negri, A. (2005). Multidão (Clovis Marques, Trad.). Record.

Lacan, J. (1988/1964). O seminário, livro 11: os quatro conceitos fundamentais da psicanálise. Jorge Zahar.

Lacan, J. (2002/1974-75). RSI (Versión crítica). Publicación para circulación interna de la Escuela Freudiana de Buenos Aires. Mimeografada.

Le Bon, G. (1963/1895). La Psychologie de Foules. PUF.

Lebrun, J-P. (2008). A perversão comum: viver juntos sem o outro. Companhia de Freud.

Lévy, P. (1999). Cibercultura (Carlos Irineu da Costa, Trad.). Editora 34.

Mansano, S. (2011). Para além da escolha profissional, experimentações intensivas. Psicologia em Revista, 17(1). http://pepsic.bvsalud.org/ scielo.php?script=sci_arttext\&pid=S1677-11682011000100006.

Marteleto, R. (2001). Análise de redes sociais - aplicação nos estudos de transferência da informação. Ciência da Informação, 30(1), 71-81. https:// doi.org/10.1590/S0100-19652001000100009. 
Marx, K. (1982). O Capital. Imago.

Nietzsche, F. (2001). A gaia ciência. Companhia das Letras.

Pichon-Rivière, E. (1998). O processo grupal. São Paulo. Martins Fontes.

Recuero, R. (2009). Redes sociais na Internet. Sulina (Coleção Cibercultura).

Rolnik, R. (2013). As vozes das ruas: as revoltas de junho e suas interpretações. Cidades rebeldes - Passe livre e as manifestações que tomaram conta das ruas do Brasil. Boi tempo Editorial.

Santaella, L. e Lemos, R. (2010). Redes sociais digitais, a cognição conectiva do Twitter. Paulus.

Santos, V. L. C. \& Santos, J. E. (2014). As redes sociais digitais e sua influência na sociedade e educação contemporâneas. Holos, 6(30), 307-328. http:// www2.ifrn.edu.br/ojs/index.php/HOLOS/article/view/1936/pdf_144.

Sucksdorf, C. (2011). Del temor a ser tocado: masa y subjetividad. Topía Editorial. Tavares, W. e Paula, A. (2015). Movimentos sociais em redes sociais virtuais: possibilidades de organização de ações coletivas no ciberespaço. RIGS, 4(1), 213-234. https:/ / portalseer.ufba.br/index.php/rigs/article/view / 9822/11588.

Torres, C. (2009). A bíblia do marketing digital. Editora Novatec.

Viana, A. M. (2013). As multidões de junho de 2013 no Brasil: o desafio de explicar e compreender. Revista Espaço Acadêmico, (36-48),

Wenger, E. (1998). Communities of practice: learning, meaning, and identity. Cambridge University Press.

Zizek, S. (2011). Em defesa das causas perdidas. Boitempo.

Žižek, S. (2012). O ano em que sonhamos perigosamente. Boitempo.

Žižek, S. (2013). Menos que nada: Hegel e a sombra do materialismo dialético. Boitempo

Žižek, S. (2015). Problema no paraíso: do fim da história ao fim do capitalismo. Zahar. 